\title{
Evolving Social Insights from E-Listening to E-Seeing: The L'Oréal Case
}

\section{La evolución de} los insights desde la escucha social a la lectura por imagen: El caso L'Oreal

\section{Estefanía Yagüez Lorenzo} Market Intelligence and Consumer Insight Director L'Oréal

estefania.yaguez@loreal.com

Alberto Rodríguez Romo

Market \& ROI Insights Leader L'Oréal

Alberto.RODRIGUEZROMO@loreal.com
Yagüez Lorenzo, E. y Rodríguez Romo, A. (2020)

Evolving Social Insights from E-Listening to E-Seeing: The L'Oréal Case

Revista Internacional de Investigación en Comunicación aDResearch ESIC. № $23 \mathrm{Vol} 23$

Segundo semestre, julio-diciembre 2020 - Págs. 8 a 29

https://doi.org/10.7263/adresic-023-01 
JEL Classification:

M31

Key words:

Social listening,

e-seeing,

artificial intelligence,

machine learning,

facial recognition
Purpose: Show how L'Oréal Spain evolved from a classic social listening practice, to image driven insights by the usage of Al tools; the first step to correctly understand the vast amount of personal information, interests and desires that millions of consumers share every day in social networks.

Design / Methodology / Approach: Hybrid approach, combining Al to quickly categorize, filter and run a preliminary analysis on images, with a manual coding of specific elements about the beauty industry. This procedure achieved two significant goals:

- First-hand learnings that could be directly used by marketing teams,

- A deep coded beauty image database that could be used to train Al algorithms in the future for a more powerful, automatized tool.

Results: There are seven main tribes within the makeup universe in Spain, based on their techniques and products used. Furthermore, its evolution was also traced, and measured within customers, influencers and brands, to detect where a 'sweet spot' was taking place: a rising trend that was growing fast among consumers and influencers, but where brands were not yet present.

Limitations / Implications: The main limitations of the study are two. On the one hand, the representativeness of Instagram for the Spanish beauty consumer. It was necessary to weight the different segments of the sample to reach the right, balanced conclusions. And on the other, Al algorithms capacity to code and filter images. At a certain stage, it was necessary to introduce human help to validate and perform a deeper coding.

Contribution: Setting the first milestone on social image insights for the beauty industry, advancing from a purely text-based insight practice to a much richer information based on the looks that consumers share every day.
RESUMEN

\section{Clasificación JEL: \\ M31}

\section{Palabras clave:}

Escucha social, lectura por imagen, inteligencia artificial, aprendizaje automático, reconocimiento facial
Objetivo: Mostrar la evolución de L'Oréal España desde un modelo tradicional de escucha social basado en texto, al análisis de imágenes a través de herramientas de Inteligencia Artificial (IA); el primer paso para entender la ingente cantidad de información personal, intereses y deseos que millones de consumidores comparten cada día en redes sociales.

Diseño/metodología/enfoque: Enfoque híbrido, combinando IA para la rápida categorización, filtrado y análisis de imágenes, junto con una categorización manual de características específicas sobre la belleza. Esta metodología permitió alcanzar dos metas significativas:

- Aprendizajes preliminares para los equipos de marketing, de aplicación inmediata

- Base de datos específica en belleza con información muy detallada, para «entrenar» futuros algoritmos de IA y crear herramientas más potentes y automatizadas.

Resultados: Existen siete principales tribus en el universo del maquillaje en España, basándonos en las técnicas y productos que utilizar. También se midió su evolución en grupos independientes de consumidores, influencers y marcas, para detectar las mejores oportunidades de inversión y tendencias en auge.

Implicaciones/limitaciones: Las principales limitaciones del estudio son dos. Por un lado, la representatividad de Instagram sobre la consumidora de belleza en España. Es necesario ponderar las diferentes celdas de la muestra para alcanzar las conclusiones correctas y balanceadas. Y por otro lado, la capacidad de los algoritmos de IA para codificar y filtrar imágenes. En un determinado punto, es necesaria la interacción humana para validar y codificar en mayor profundidad los resultados preliminares.

Originalidad/contribución: Interpretación de imágenes en redes sociales para la industria de la belleza, avanzando desde el análisis de textos a una información mucho más rica y basada en imágenes que las consumidoras comparten en redes sociales. 


\section{Background: From social listening to e-seeing ${ }^{1}$}

The interest of the market research industry for what consumers share in digital media begins with the launch of the so-called Web 2.0, which put in the hands of almost any user the possibility of expressing themselves through these platforms without the technical and economical barriers that hindered the democratization of this practice. Suddenly, millions of users began to share their opinions and experiences related to consumption and brands, which was quickly perceived by the industry as an opportunity to complete consumer knowledge obtained through traditional sources (surveys, focus group, consumer panels, etc.). Rather than sampled consumers, for the first time it was possible to listen to the true, unfiltered consumer opinion on a real time basis (Celaya, 2008).

Almost at the same time, a parallel industry, that of "Social Listening", was also developed, led by small technology companies, which put on the market tools that allowed the collection and analysis of what was published on the Social Web from text-based queries. After setting one or more keywords, these tools connect to the databases of social networks, via API, extract the contents in which there is a match with those keywords, store them and analyze them, both quantitatively and qualitatively. In short, these are tools whose main value for the consumer research industry lies in analyzing "what is written", the word.

The development of commercial Social Listening tools coincides with a period (mid-last decade) in which the Social Web was dominated by platforms in which the text had a clearly greater weight than the image, as was the case of

1 Thanks to: Nethodology \& Microsoft the forums and blogs. As a consequence of this preeminence of the text in the origins of the Social Web, both in the academic field and in the industry itself, much more effort and resources have been devoted to text mining, in general, and to semantic analysis, in particular, than to image analysis. In fact, the sharpness of the semantic analysis was the key element of these tools, ultimately determining their potential. Not an easy task, actually: often sarcastic expressions, acronyms, passive voice expressions and other related verbalizations were not always correctly identified by the tools and categorized incorrectly as a 'positive' or 'negative' reaction being the opposite case. These tools have always required a strong database to start with, constant updates and to a very large extent, human supervision and fine tuning (Romero \& Gil, 2008).

At the end of the last decade, two great technological revolutions occurred that would end the hegemony of the text on the Social Web. On the one hand, the penetration of the mobile Internet radically increased, bringing connectivity to a device equipped with a photographic camera. In parallel, Facebook reaches the "Tipping Point", thanks in turn to a large extent to the development of the Mobile Internet. Facebook is the first massive social network that facilitates and promotes communication between users based on images (mostly photos). A few years later, Twitter, which was born as a social network oriented to written communication, would migrate towards audiovisual communication. Later on, Instagram emerged, giving the text an almost residual role, purely related to hashtags for visibility, topic search and connections (IAB Spain, 2018).

While these transformations were taking place, the "Social Listening" industry and monitoring tools stayed anchored in the "textual" dy- 
namics of the origins of the Social Web. This meant not only a loss of lots of information that consumers were sharing in social networks, but also a real challenge for sectors, such as beauty or fashion, in which the user is constantly communicating their tastes and preferences in these consumer categories, even when the message they want to convey has nothing to do with it. In practically any photo uploaded to Instagram in which a person appears, there will almost certainly be an outfit, a hairstyle and a facial look (even if it is a completely clean face). Suddenly, missing out your consumers' communications in channels that were so disruptive had become a risk for brands. If you were not able to be in touch with your consumers in a moment when they are broadly sharing most of their private life publicly, you could be perceived as an out of date brand, losing the connection with your audience. (Borgatti, Everett \& Johnson, 2018).

By the late 2000's, some technological revolutions disrupted the social networks universe. Firstly, smartphones were massively adopted, giving online access to users equipped with increasingly better cameras. In parallel, Facebook drastically switched its philosophy to a mobile, more image-based network; as an example, to illustrate this strategy mindset, they even had 'mobile only days in the Facebook HQ, where all laptops were shut down and it was only possible to work via mobile-. Later on, Twitter enabled better visual content on their feeds. Finally, Instagram disrupted the market with a pure image-based concept, with very little importance given to text. Due to high user engagement rate, Instagram also a valuable social media marketing tool. The most important consumer socialization variables are with an emphasis on peer communications, brand related factors, and the use of the social network for eWOM among the users of Instagram. When consumers follow brands in a social network, the brands may create their desirable attitudes and build loyalty in consumers. In addition, engagement through social media platforms can play a very important role in building brand relationship quality. By studying how users imitate the behaviour of other users and their attitudes towards brands, they can distinguish the users' perception of relationship quality, their use of social networks, the number of brands that they follow, and the individuals who participate in brand-related eWOM. This distinction can help marketers discover the most likely perspective of brand management. (Delafrooz, Rahmati \& Abdi, 2019).

Facebook quickly perceived this emerging trend and purchased the booming app for the sum of \$ 1Bn in April 2012. Considered a rip off by then, now Facebook's stock is worth four times its 2012 average price —and complementing its mature founding social network with a fresh, younger and wildly image based platform has definitely played a big role into it. Not only image is trending, but it is also demanded by youngsters - the most intensive users of social networks (Borgatti et al., 2018).

Furthermore, in the following years, all disruptive approaches in the social network market - such as Snapchat stories, which were later replicated by Instagram- were purely visual. The latest trend is Tik Tok, a 100 \% video-based network based on short interactions from three to 60 seconds. Consumers happily embraced this shift and massively adopted the image-based communication, therefore limiting the room for precise text analytics. In a context where an image tells a thousand words, text is only used to mention, link, or cheer up, rather than providing an insightful context about a consumer's feelings or likes. 
Lots of visual information with key insights was being missed due to social listening limitations. In this situation, moving from text-based social listening to image-based, or e-seeing, was not only a logical next step, but also an absolute need to continue to be in touch with consumers. As the world industry leader, it is a must for L'Oréal to understand how people connect, engage, share and enjoy their beauty across ages, genders and likes, helping marketers to match the right audiences, in the right moment, with the right content, through the right channels (Borgatti et al., 2018).

The very name of the technique- Social Listening - already hints that the focus is on the text; an example of a typical output can be seen on Figure 1. You "listen" to what is "said", what is "written". As it has been exposed, this approach leaves out something tat in consumer research is essential: "what is done", which, transferred to the context of social networks, would be "what is shown". "We listen", but we do not "see" (Ramos et al., 2020).

In conventional qualitative research (through ethnography, focus group, in-depth interviews, etc.) the advantages of image analysis are well known. They are used, for example, to allow consumers to express ideas that are repressed (consciously or unconsciously) or that are so complex that people find it difficult to verbalize them. They are also used for the user to project (as in the collage technique). And, of course, they play a fundamental role in ethnographic research by providing context information that hardly appears when other forced context techniques are used, such as focus groups (Malhotra, 1996; Silverman, 2016).

These same advantages are fully extrapolated to research on social networks. There are millions of users who have stopped talking to start showing. It may be asked then why even today the analysis of images published on social networks continues to be marginal. It is necessary to adopt new tools and develop methodologies that incorporate this source to enrich analyses and obtain better insights. In short, move from Social Listening to e-watching.

Now, more than ever before, ethnographers are using visual and digital images and technologies to research and represent the cultures, lives and experiences of other people. Theoretical and technological innovations have made the visual both acceptable and accessible to anthropologists and this has created a contemporary context where new ethnographic media, methodologies and practices are emerging (Alfonso, Kurti \& Pink, 2004).

Artificial intelligence, a great ally. Internet monitoring tools have begun to take some timid

\section{Figure 1. Classic text query results and topic analysis}

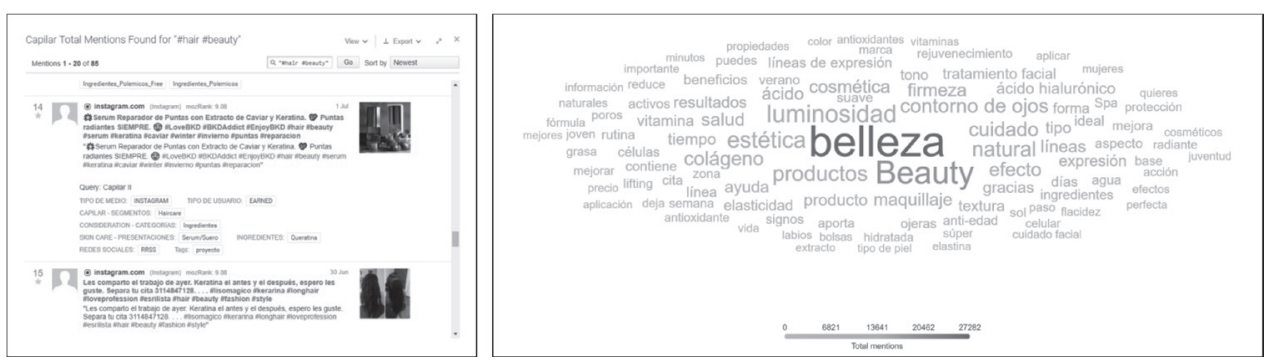


steps for tracing images in which an object of interest for research appears. Several of the most relevant tools in this market already have functionalities that allow, for example, detecting images in which a brand logo appears, even if it is not mentioned in text.

These advances, still clearly insufficient, have been possible thanks to the technological boost given to image recognition by Internet big players, with Google, Amazon or Microsoft leading the way. Their need to analyze, classify and moderate the vast amount of images published every minute on the Internet is behind the speed with which these technologies, supported by artificial intelligence, have been developed and democratized. And of their own need, these companies have found a new market niche that involves making these technologies available to third parties. Google has Cloud Vision, a service via API, which allows to extract information from images, such as a wide catalog of objects, recognition of logos or faces, and create new custom models.

With time, these tools further developed and enabled a series of relevant insights, such as incorporating objective information from the users' profiles in social networks, or improving the semantic analyses to understand the consumers' sentiment towards a product - whether positive, negative or neutral, as appreciated on example Figure 2. This was particularly relevant for understanding customers' profiles, to manage specific crises or to analyse the brand engagement through time, although again, purely based on text interactions (Alfonso et al., 2004).

As above mentioned, the limitations of these tools are considerable, while the possibilities that e-seeing offers are huge. And not only in terms of insight, but also on scalability. A language processing tool faces constraints when switching to a different language (or even between different language regions, as Spain or Latin America could be), and needs to be thoroughly reviewed. On the other hand, image processing has the enormous power to be automatically escalated to any other country with very minor tweaks. If you can train a tool to detect and filter a specific element in an image, that element can be traced in any picture taken around the world; now imagine the potential that this can have applied to a global scale. In the case of L'Oréal, it can be possible to leverage local developments, and a small initiative can completely change the way the entire organizations relates with their customers in a relatively short period of time - definitely shorter than the usual timings needed for long-scale organizational changes (Kaneshige, 2015).

\section{Figure 2. Gender, interest and sentiment analysis}
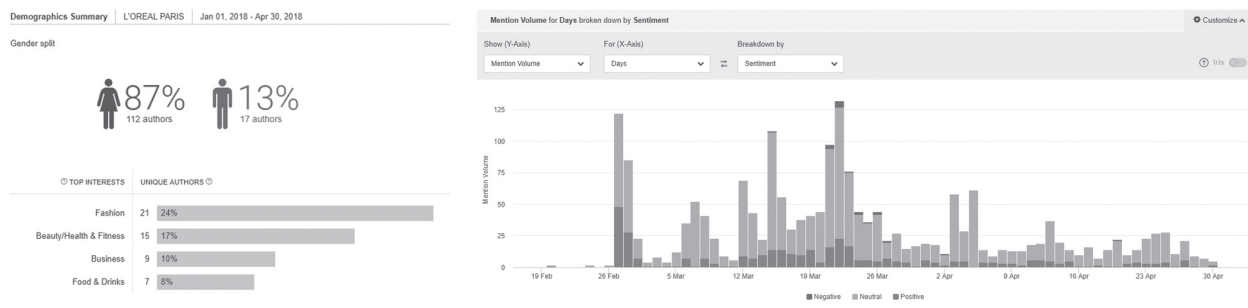
Figure 3. Deep Vision make-up landing screen

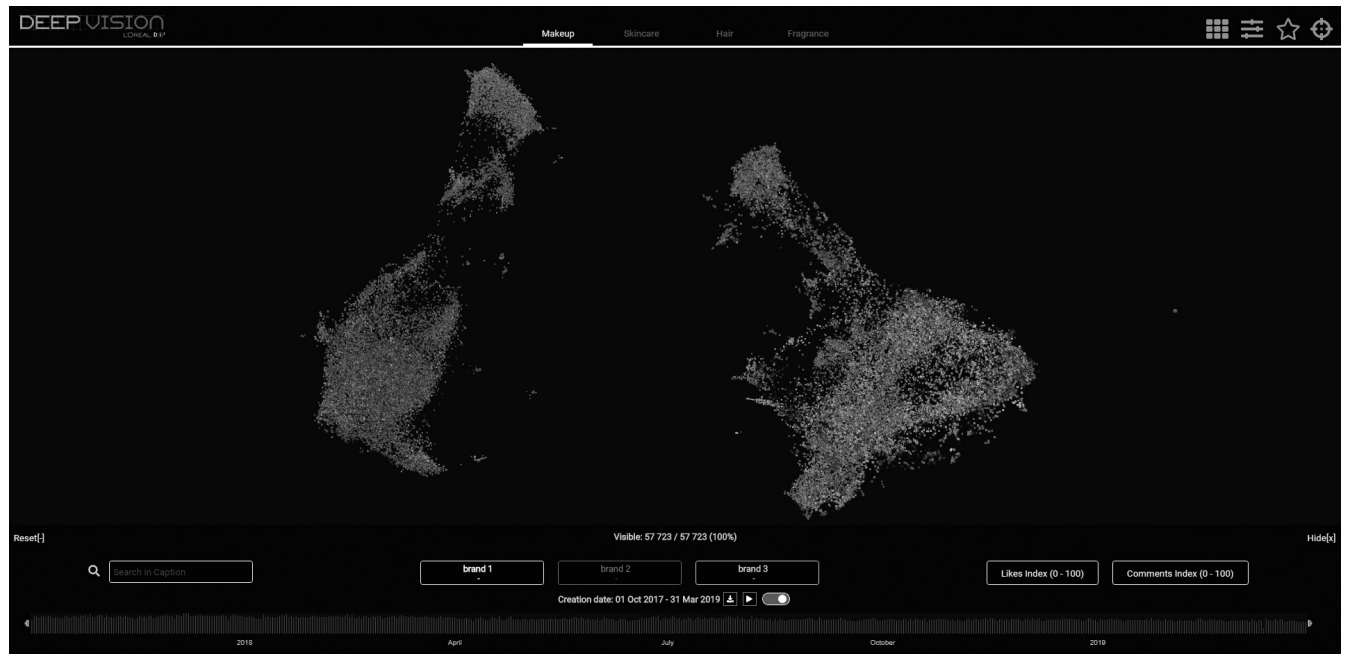

\section{Figure 4. Deep Vision zoom on eye make-up and NYX professional make-up}

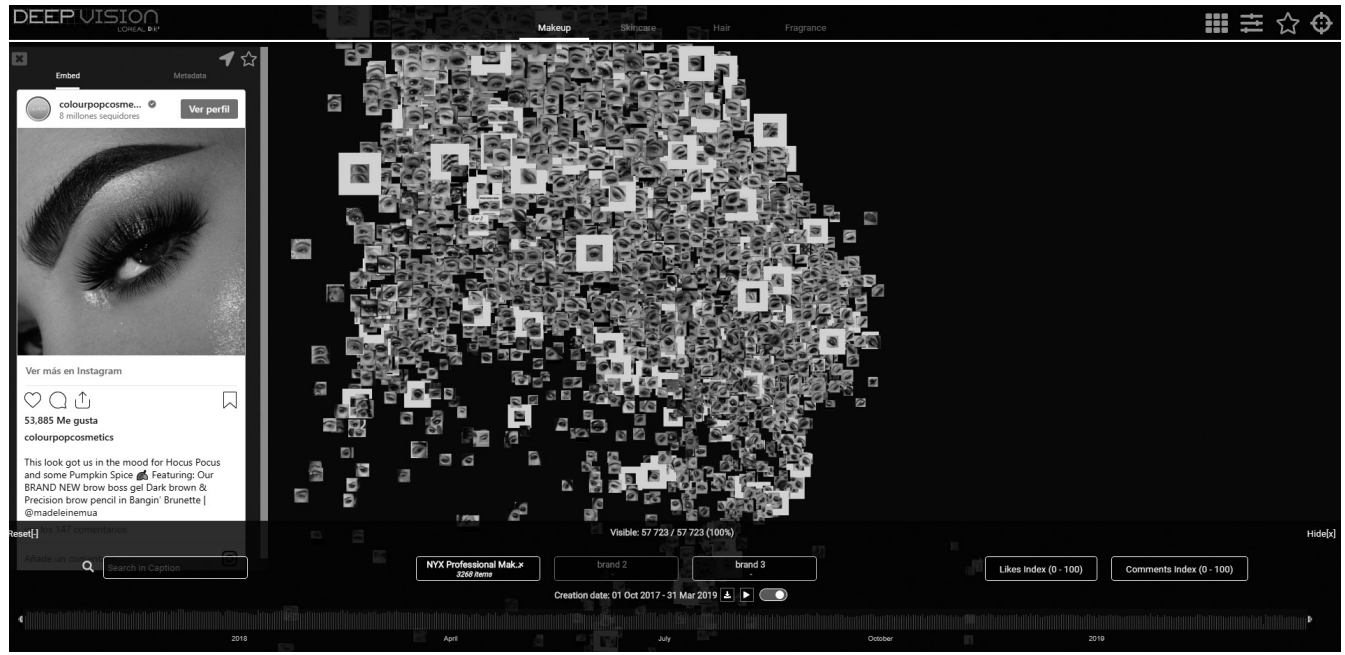

L'Oréal itself is an example on how image-based IA can be easily escalated, not only geographically, but also in the way that a similar algorithm (identifying objects in an image) can be utilized for different functions. The following tools were recently deployed within the LOréal insights community and have helped the teams since:
- Deep Vision (Figures 3-4): Image recognition and linkage to other similar ones on Instagram, enabling the classification of over 50,000 images into different clusters of similarity and tracing of its brand. Visualization shown below.

This tool enables L'Oréal teams to monitor the key trends and competitor activity, as well as ad- 


\section{Figure 5. GoldenEye interface and results}

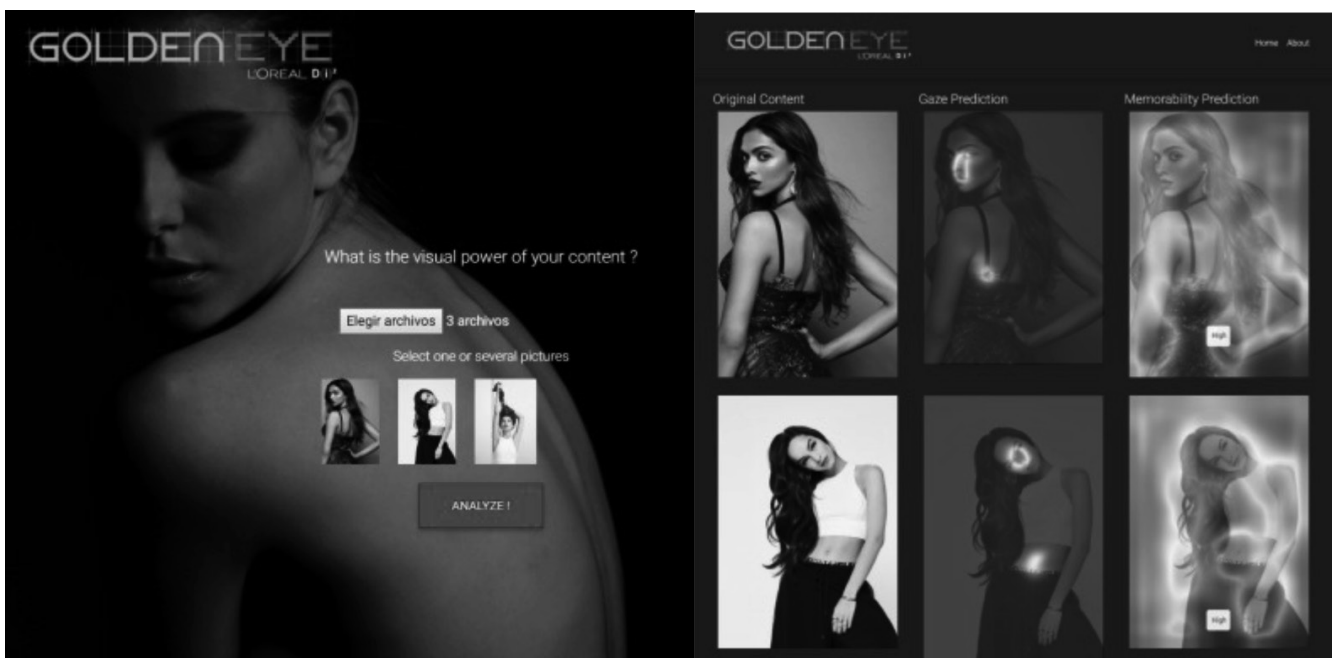

just campaign investment weights based on their axis strategy. It is also used to visualise examples around given trends.

- Golden Eye (Figure 5): the same algorithm, but focused on quick and sharp image selection for marketing teams. This tool highlights the most relevant elements of a picture and contrasts them with Microsoft's and MIT's database of neuronal studies: over 70,000 cases in total to match with our algorithm, to predict image salience and memorability. This way, marketing teams can quickly make choices between multiple ambassadors, creativities, product images and image compositions, with a solid criteria behind and with the help of AI.

\section{The approach of L'Oréal Insights: Partnering with $\mathrm{Al}$}

When first facing the challenge of making this relevant shift, the L'Oréal Consumer \& Market Intelligence team searched for inspiration among well known traditional techniques. Additionally, in the same way images were a great support for conventional qualitative techniques, the goal was to develop similar capabilities, but with a more ambitious scope. In traditional qualitative research, showing images directly to consumers is often a good approach for gathering firsthand, direct reactions, but it is also useful to use projection techniques to dig deeper into consumers' feelings, and understand the underlying perceptions that matter the most - the true insight. Translating this philosophy into e-seeing, the goal was to not only perceive the evident, but also spot the trend, identify the tribe and separate trend-setters from the followers. At the opposite end with a pure tech approach, AI was taking its first steps into the social listening industry. The first tools enabled logo identification within sets of images, or basic information: gender, age, etc. Gradually, big players entered the market, such as Google with Cloud Vision, or Microsoft with Computer Vision. These were more powerful tools, enabling a deeper analysis for the Consumer \& Market Intelligence teams (Mulfari, 2016; Del Sole, 2017). 
Figure 6: Microsoft's computer vision lip make-up detection

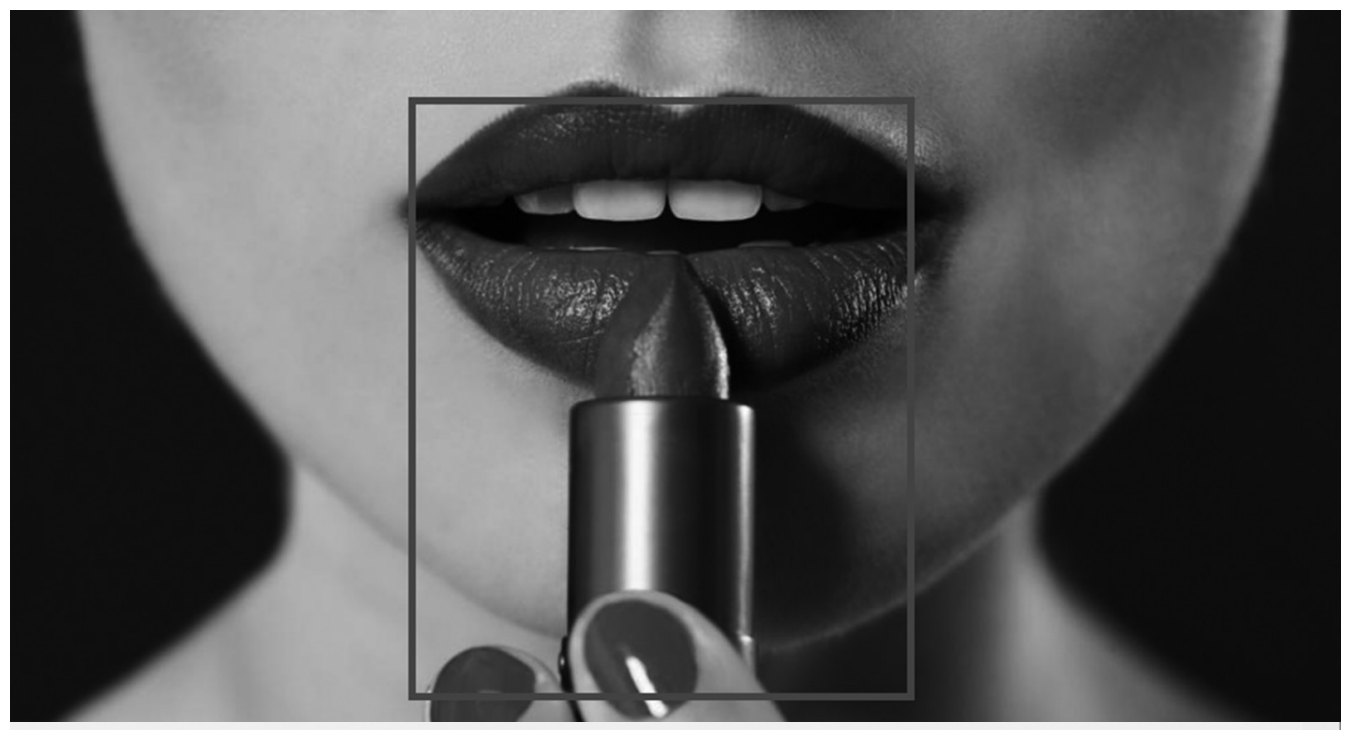

NOMBRE DE LA VALOR

CARACTERÍSTICA:

Objetos

[ \{ "rectangle": \{ "x": 297, "y": 62, "w": 372, "h": 444$\}$,

"object": "Cosmetics", "confidence": 0.666$\}$ ]

Etiquetas

[ \{ "name": "lipstick", "confidence": 0.995054841$\},\{$

"name": "cosmetics", "confidence": 0.993185163$\}$, \{

"name": "indoor", "confidence": 0.9231032$\}$, \{ "name": "lip

gloss", "confidence": 0.9047066 \}, \{ "name": "eye shadow",

"confidence": 0.8532623 \}, \{ "name": "eyes", "confidence":

0.8496293 \}, \{ "name": "mascara", "confidence": 0.838762 \},

\{ "name": "lip", "confidence": 0.8240551$\}$, \{ "name":

"wearing", "confidence": 0.8149958$\}$ \}, \{name": "eyelash",

"confidence": 0.7974565$\}$, \{ "name": "nail polish",

"confidence": 0.7523154 \}, \{ "name": "mouth",

"confidence": 0.738652766$\}$, \{ "name": "eye liner",

As shown in Figure 6, a proven algorithm such as Microsoft's can be a great help to filter out massive amounts of social interactions and set the base for analysis. This was enables to quickly find the images with, for instance, makeup on display, but it was necessary to go further to better understand the beauty consumer. Make-up is all about the trend. To be successful 
in the make-up industry, it is a must to anticipate the trend, jump into it, validate its adoption and anticipate the next one. Companies strive to be two steps ahead, so it is possible to even set the next trend, rather than following it. Unfortunately, the necessary information to gather these insights is not covered by standard algorithms: you could search for lip make-up, but not lip contouring make-up, nor matte ink texture lip make-up.

This was the basis for L'Oréal's hybrid approach. The need was to reach the agility of AI with the power of a deep, thorough database that could only be created with our expertise in the beauty industry. Leaning on an available solid technology, the Consumer \& Market Intelligence team could train and develop machine-learning algorithms to extract deeper insights about the beauty universe. This is how it was decided to merge the available standard AI and complement it with an in-house codification, building a solid and exhaustive database, to deeply understand the beauty consumer in social networks in a purely image-based environment.

Opting for one of these services was the first milestone. Knowing that the project needed the help form a best in class software developer, Google's and Microsoft's propositions were evaluated to understand which one would not only meet the needs, but also be scalable to a more ambitious macro project with a worldwide scope, and that could be seamlessly integrated into L'Oréal's IT infrastructure.

In summary, the primary list of mandatory requirements included the following:

- The capability to trace, identify, and categorize beauty elements in a picture - not just the core but also any potentially relevant elements within the picture perimeter.
- These items could be physical objects (e.g. a lipstick) but also body parts (e.g. lips) and even characteristics that could define them (e.g. makeup applied).

- The capacity to, based on a set of requirements, filter large sets of pictures based on either image characteristics (e.g. face being shown), texts (e.g. a given hashtag). This was a must to build and prepare the image databases required for the analysis.

- The advanced capability to infer objective elements based on image, e.g. the consumers' age. Closely linked to the necessity to filter and categorize large sets of images in order to have a solid database.

- Possibility to read, interpret and translate texts in different languages.

- The ability to be integrated into L'Oréal's IT systems seamlessly.

Both Google and Microsoft tools proved to be very solid and perfectly capable of performing these tasks. In the end, the easiness to implement it into the already existing IT systems was the final element that moved the needle. Nevertheless, both suites made a good match with the requirements.

\section{The design: Scope, objectives and process}

As our first approach into e-seeing, the scope of the analysis was set onto the following aspects:

- Make-up and hair as the most relevant categories in which consumers do usually express their beauty.

- Regarding hair, the focus was placed more on hair colouring. In the moment of the analysis, strong trends were hitting the market and the need to address them was big, and also easier to identify. 
- Hair care, on the other hand, despite being a large category in terms of sales volume, is not an aspect consumers -nor influencersare keen on communicating on image networks like Instagram. It is more frequent to see youtubers communicate on these types of products, sharing tips and tricks and beauty rituals.

- Styling was a similar case, being the \#1 category in terms of beauty related content in social networks (even more than makeup). Both on video tutorials or on final look shots -and all the intermediate options, step-by-step pics, gifs etc. every day consumers, influencers and brands show you how to achieve the trendiest looks. However, despite being a great showcase for brands, here the category size was a determining fact and it was decided to favour make up and hair colour. Also, it was neither an easier category to work with. Despite in our minds a given look can be very easy to identify, like braids for example, it spans a diverse range of appearances in real-world, thus it is very difficult to use hand-designed image features to recognize [...] (Sun \& Won-Sook, 2017).

- Instagram was the social network chosen. While this technology can be potentially applied to any social network displaying pictures, such as Facebook or Twitter, Instagram was preferred for being the platform where beauty is displayed at its best, where the trendiest fashion and beauty influencers share their content (Hu, 2014). Also, because it is one of the platforms that has shown best how to adapt in a highly volatile environment, while enabling an open space for brands to participate and collaborate in a constructive relationship. Probably its best example was the fast enablement of the stories' capabilities to counter attack Snapchat, now a less relevant network. The constant evolution of Instagram, striving to include sound improvements year over year -such as Live or Shopping- made us anticipate that this one is here to stay, and that any effort put into this network nowadays it's going to have a future to pay its dividends.

- 2017 and 2018, the latest full years by the time of the analysis. As beauty trends are fast and volatile, it was decided not to go further back in time.

With the ultimate goal of improving our digital ROI, a series of objectives followed, closely linked to the way L'Oréal usually activates social and digital media:

- Understand the current and rising trends on make-up and haircare across brands, influencers and consumers. Learn how these segments interact and balance the true weight that each of these segments has in the social conversation;

- Validate the usage habits and techniques;

- Detect styles, tribes and weight them based on their relevance and evolution.

The overall process, as shown on Figure 7, consisted of five stages that led to very relevant insights, set the basis for internal AI developments and inspired the Consumer \& Market Intelligence team to elevate the reach and depth of social media analysis across the company.

\section{a. Massive image collection}

To set a solid base for the analysis, seeding a database with insightful images that could teach us all about beauty trends was necessary. To do so, 


\section{Figure 7: The path from social listening to e-seeing}

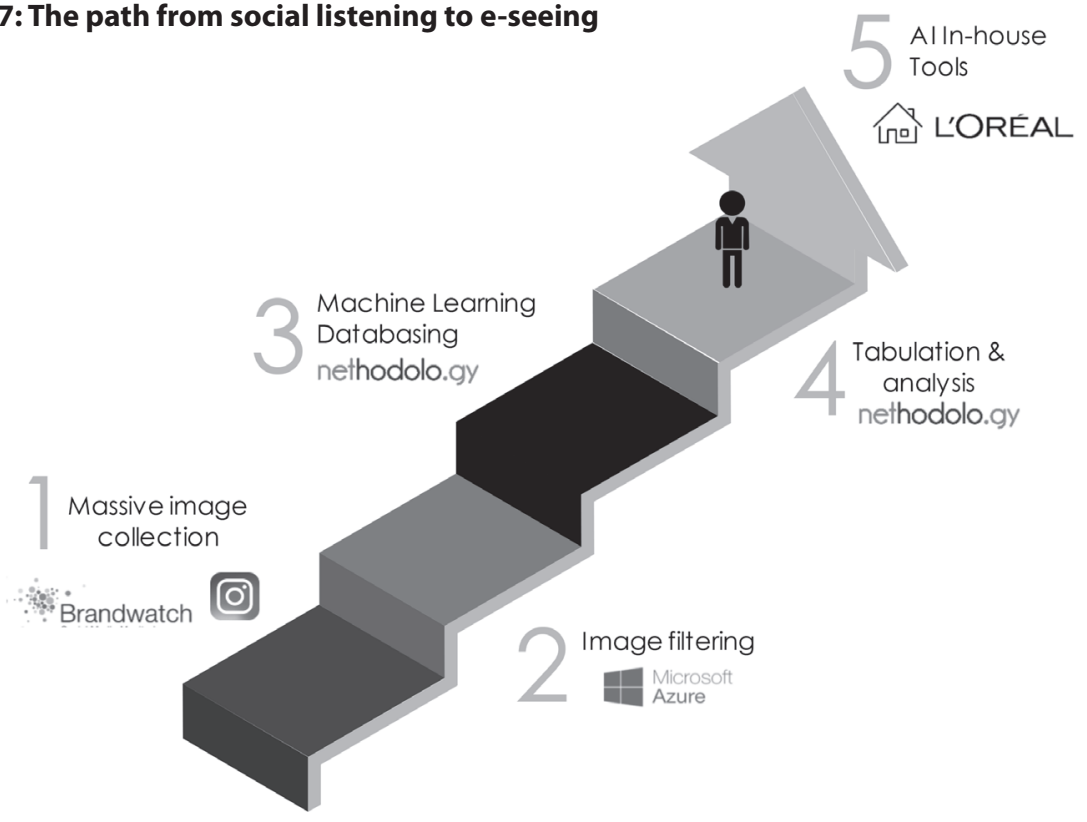

all relevant images from Instagram between 2017 and 2018 with the following characteristics were scraped:

- Users (<10k followers): Based on a set of relevant keywords.

Traditional social listening helped a lot on this task. With traditional language-based tools the team was already tracking the activity on these networks, so the trendiest hashtags and queries were already well known, and therefore leveraged for the database seeding.

- Brands Top 15 beauty brands in Spain with Instagram account. The relevancy here was not just to select the largest brands, but the most relevant ones online. Lately very small players have entered the beauty industry due to the relaxation of traditional entry barriers: influencer marketing is affordable even for small players, scale production can be bypassed through China, and online distribution can quickly cover an entire country. These brands are agile, have the advantage of being brand new to consumers, and know how to talk to them in their own language with a $100 \%$ digital communication. As a result, their presence in the online community is significant, their communication is trend setting and therefore worth studying. Furthermore, some smart brick \& mortar retailers have spotted these trends and incorporated them into their portfolio as exclusive brands, expanding their footprint and novelty factor with a very significant footprint whilst keeping their sense of newness and exclusivity.

- Influencers (>100k followers): top 32 local influencers identified in beauty campaigns. 
Again, we leveraged the social listening textbased tool Brandwatch. Starting from the list of the most relevant influencers, a list was defined to cover the widest spectrum of positionings: natural, highstylers, modern, etc. both collaborators and non-collaborators of L'Oréal.

The KPI for selection was ultimately engagement, measured via $n^{\circ}$ of likes. This metric was preferred over followers because of its higher reliability. Also, as influencers pop up and its relevancy is more contested, some obscure practices such as 'buying followers' are becoming sadly more common, and engagement metrics (important: over a sustained period of time) are often a better surrogate of having a true base of followers behind. Nevertheless, the lines are still blurry on this aspect, as it is also common that as influencers become widely notorious, their engagement rate gets lower (3\% would be a decent level for a top-of-the-list influencer) than 'rising stars', that normally have a more loyal base and their engagement levels can easily be above $5 \%$. Here the help from PR teams was very valuable to set the lines.

After this process was completed, a preliminary set of over 10,000 images was collected and databased, ready to start applying the AI tools onto them.

\section{b. Image filtering and sample definition}

Once seeded the database, the next step was to apply the first layer of filtering to discard all the images that were non-usable, or that could introduce an undesired bias in the analysis. The filtering criteria used were the following:

- Gender: female. Despite the beauty trends are present also in men, and growing at an encouraging rate, still their presence and activity in social networks proactively communicating about beauty is rather limited.
- Age: at least 18 year old

- Image composition: Face must represent at least $25 \%$ of the total image size, in order to provide enough detail for the tools to trace all relevant elements, often subtle such as the wing of an eyeliner. Additionally, the image could not have any element that may limit considerably the amount of insights we could get from it - such as sunglasses.

Another key task of this stage was to classify the images, using the tool to set a series of objective codes for every picture, as can be seen on Figure 8:

- Make-up: type of make-up applied (e.g. mascara, lipstick, eye shadow, nail polish, etc.);

- Hair: colour, layered, length, etc.

This tagging feature was indeed the most valuable ones provided by Computer Vision. Despite being part of its stock capabilities, it made possible to quickly filter and classify an amount of information that would otherwise have been unbearable for human standards - it would have taken ages and an overwhelming cost. Once finished, a set n=400 images were already filtered, pre-coded and pre-classified by category.

\section{c. Machine-learning databasing}

This was the last step in the preparation process, right before starting with the results' analysis. It was here where the human validation was necessary, for two main reasons:

- Validate Computer Vision's algorithm and check that the final database had been correctly seeded and categorized.

- Dig deeper into the coding, moving from basic detection (e.g. lipstick, long hair) to a much more detailed one. 
Figure 8. Microsoft's computer vision hair detection

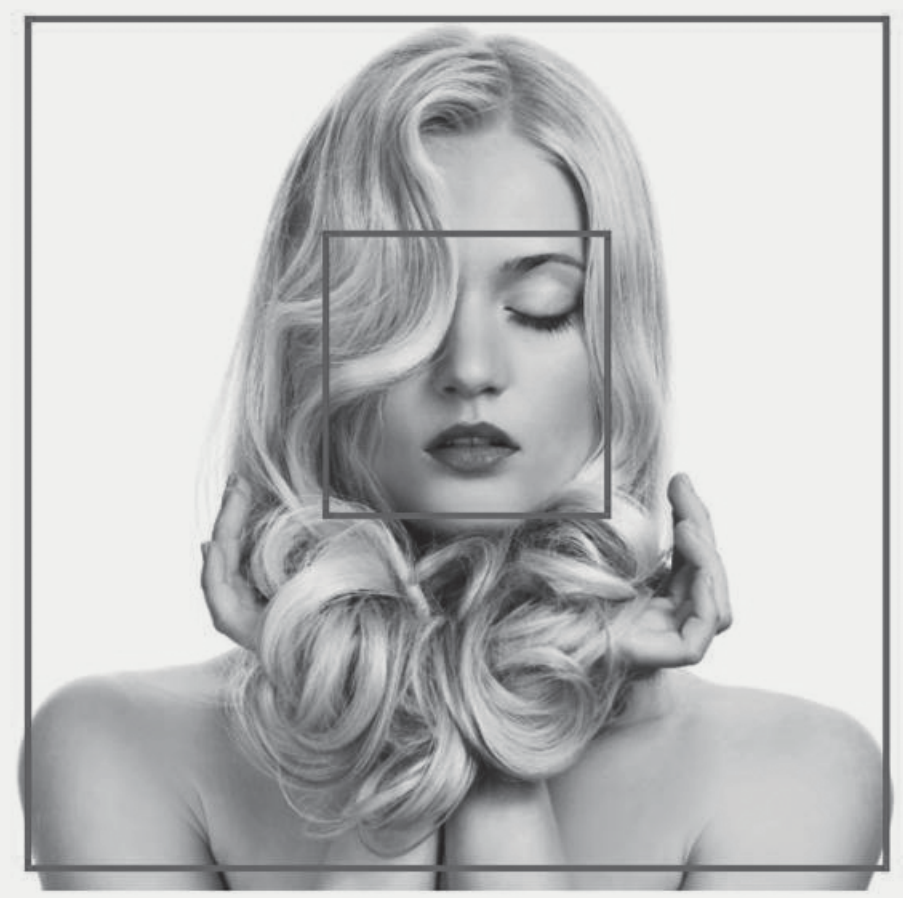

\section{NOMBRE DE LA VALOR CARACTERÍSTICA:}

Objetos

[ "rectangle": \{ "x": 42, "y": 60, "w": 949, "h": 941 \}, "object": "person", "confidence": 0.887$\}$ ]

Etiquetas

[ \{ "name": "person", "confidence": 0.9977635 \}, \{ "name": "clothing", "confidence": 0.937279046 \}, \{ "name": "human face", "confidence": 0.8733501$\}$, \{ "name": "fashion", "confidence": 0.8494519 \}, \{ "name": "fashion accessory", "confidence": 0.8220071 \}, \{ "name": "lipstick", "confidence": 0.794536352 \}, \{ "name": "blond", "confidence": 0.7895291 \}, \{ "name": "woman", "confidence": 0.771347642 \}, \{ "name": "long hair", "confidence": 0.766512752 \}, \{ "name": "beauty", "confidence": 0.7612153 \}, \{ "name": "girl", "confidence": $0.7356668\}$, \{ "name": "brown hair", "confidence": 0.676949263 \}, \{ "name": "layered hair", "confidence": 
At the current stage, this human validation feels absolutely mandatory. Among others, the main reason why AI image classification is not absolutely accurate, is because objects ofthe same class can look vastly different (Seif, 2018).

In total, more than 125 codes were enabled for tagging across all 2,400 images, to build L'Oréal's first make-up e-seeing, machine-learning enabled database. This coding process dug deeper into the trendy looks and fashionable aspects of make-up images, in order to build up on top of a basis of objective information (Figure 9). And what can be more important, it also set the base for a more ambitious process, to be considered in the future: if this deep coding can be used to develop and train a future machine learning algorithm, then this manual step can be automatized in the future. Here is where the true potential of machine learning would come into play, by learning from tedious manual tasks to improve its own capabilities and become a much more powerful tool.

\section{d. Analysis}

Finally, a solid, comprehensive and rich amount of data to work with had been created. All this information was thoroughly analysed focused on four main angles: booming trends, main looks' characteristics, relevant urban tribes and the impact of influencers. Some of these insights, and how they inspired L'Oréal teams to better activate their campaigns, are described later in this paper.

\section{The results}

\section{1 Beauty tribes. Insights and activation}

First, it was necessary to check some consistency on the sample; although Instagram usage penetration data by age range was available, it could not be extrapolated to the analysis of our particular territory. For example, while the General Study of Social Networks of the IAB 2018 revealed that $40 \%$ of users are younger than 30 years old, this research revealed that $84 \%$ of fe-

\section{Figure 9: Example of a databased image after Al and in-house coding process}

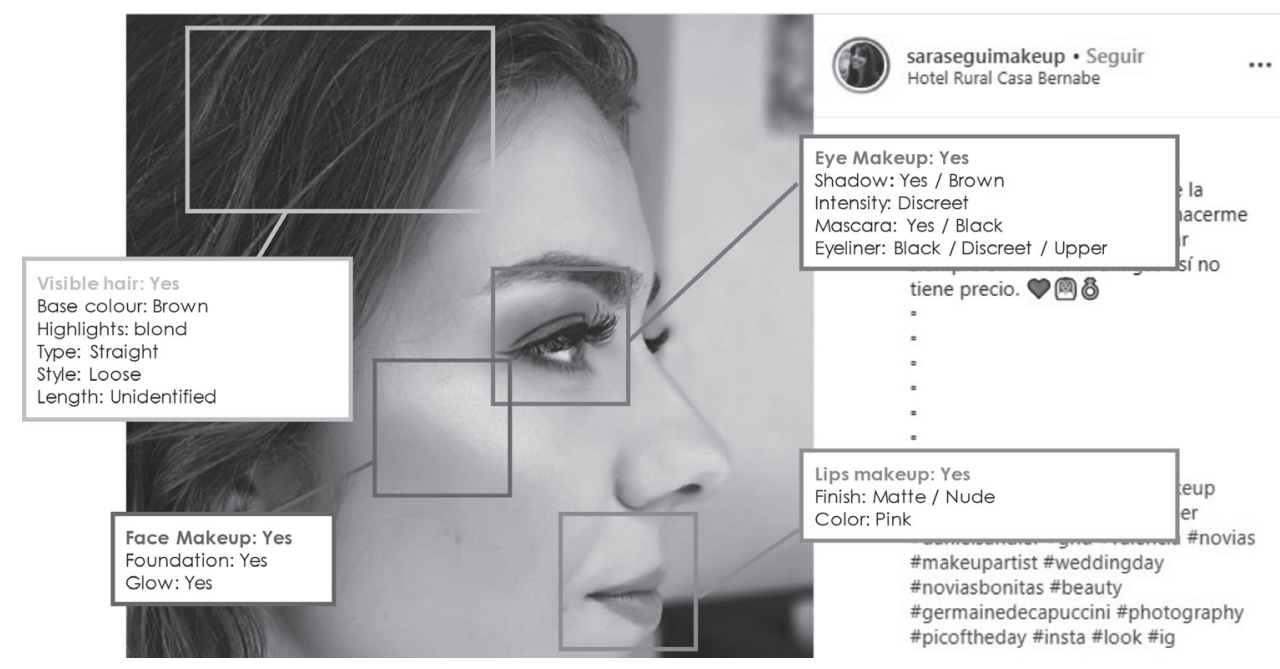


male consumers were in the same age range, with those from 18 to 22 years being the largest group (36\%). By comparing these data sources, it was verified that the penetration data of Instagram cannot be interpreted as representative of the average beauty consumer without prior weighting as these segments overindex the beauty communities.

This representativeness check should be absolutely mandatory. Counting with the help of AI should not limit the validity checks to be made upon the underlying data. Machine learning systems that have been trained on data sets that include irresponsible judgments are likely to yield irresponsible predictions as outputs (King \& Owen, 2019).

However without any doubt, the more powerful insights came from clustering the make up tribes' segmentation. Why tribes and not traditional segmentations? Segments are people to reach through media, whereas TRIBES are people to talk about through advocacy (Influencers marketing). The former are bound by similar needs and behaviors; a person can only be in one segment. They do not choose to be in a segment. Static \& long term, helps identify targets for brand portfolio strategy. In social networks, tribes are bound by passions, tensions, mindset, culture. A person can belong to more than one tribe, choose a tribe, fluid $\&$ based on social insight, helps identify advocates and generate connecting experiences.

With these data, the study focused mainly on identifying differences in consumption, using habits according to age segments in female consumers. The main finding was related to the possibility of performing analyses based on the age segments identified from the AI (Microsoft Azure).

Image analysis demonstrated how users combined the different categories and what was the final result of these combinations, to get the most successful looks. A textual analysis would not have allowed to identify clusters, since in many mentions the users do not identify all the products; much less describe the way of application.

Thanks to the cluster analysis, the team was able to identify the looks (most frequent combinations of makeup categories) and define the styles preferred by the consumer in 2017 and 2018 as well as determine the variations in these preferences.

One of the main concerns for make-up brands is how to prioritise initiatives within a huge product portfolio. A regular make-up brand has over 300 SKUs in its catalogue, and having the right magnitude of orders is key for the brand strategy. Of course, market data is a guidance, but what if the doubt lies between two product-lines that are currently minor, but it is believed they can have a solid potential? Classifying and measuring the size of looks and urban tribes was very helpful for brands in this respect. The following segmentation (see Figure 10) enabled teams to prioritise initiatives and improve their portfolio management.

As shown on Figure 10, up to 7 tribes of different looks, that we managed to stereotype, were identified: Basic, Smoking Eyes, Pink Pin Up, Working Girl, Glowy Nude, No Make Up, Classic Make Up (Figure 10). With very different weights for each tribe. One out of every three looks analyzed refers to the Glowy Nude style.

Overall, it was perceived how, from the age of 26, young women applied less frequently the cases in which they wore makeup fell 3 points - but this makeup was more sophisticated in that they used elements such as blush or foundation.

Among all these styles, the Glowy Nude turned out to be the one with the highest pene- 


\section{Figure 10. Relevant urban tribes}

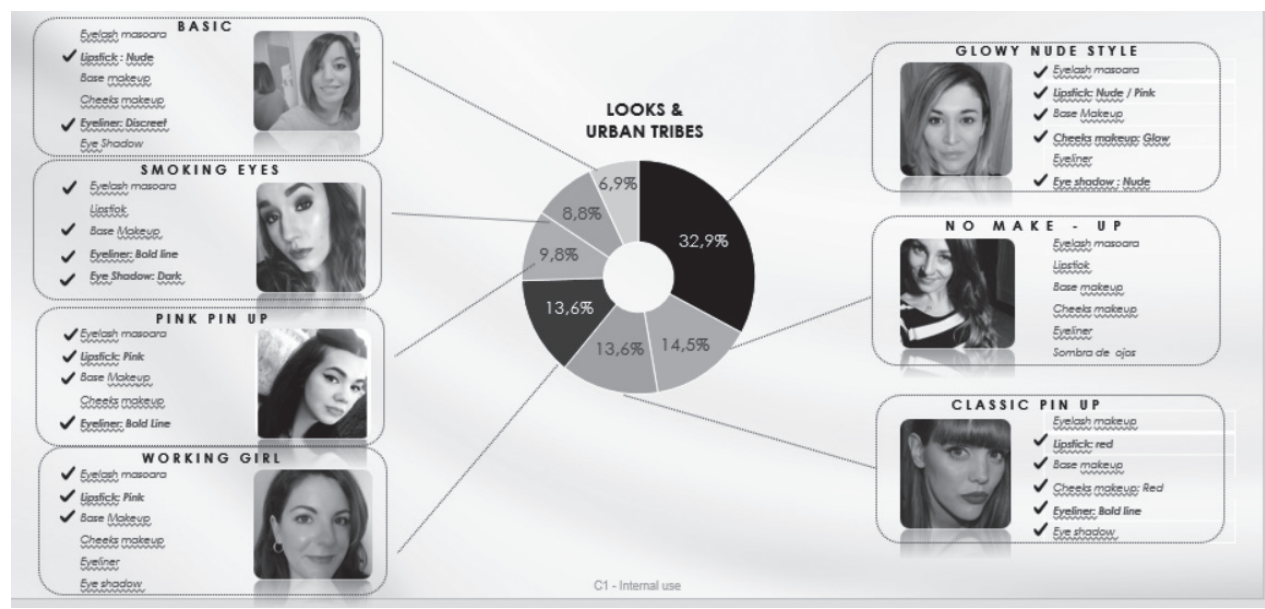

tration, and it was also the look that had experienced the greatest growth compared to the previous year, close to $10 \%$. Meanwhile, the looks "Basic", "Smoking Eyes", "Pink Pin Up" and "Working Girl" experienced declines of between $2 \%$ and $3 \%$. On the other hand, the "No Make Up" and "Classic Pin Up" styles remained at a similar degree of penetration with little variation between the two years. Therefore, it was decided to prioritize products, communications, influencers and actions focused on this trend.

One of the first insights that came up were the trendiest looks. In order to correctly address the current dominant trends and prepare for the upcoming ones, it was particularly insightful to learn how fast Glow Nude style was rising in Spain, and prioritise the launch of the "Glow Mon Amour" make-up line for L'Oréal Paris over others in the pipeline (Figure 11). In fact, by the time of the analysis, the glow trend was widespread across consumers and influencers, but under developed by brands (see Figure 11).

Another relevant learning was to see how regular consumers were becoming more profes- sional, shifting from selfies to more elaborated posed pictures. This was also used by PR teams to evolve social engagement campaigns and contests, avoiding old-fashioned image requests and asking for more engaging attitudes. A good example of this is Garnier \#beautytester campaigns.

A look is made of a set of products, techniques and characteristics, combined together to create a differentiating layout. Thanks to this new model, L'Oréal marketing teams were able to understand these relationships in every look and adapt our imagery and comments accordingly. The case of Glow Mon Amour (Figure 12) is indeed a paradigmatic one. The way consumers and influencers were communicating about the brand was in rather natural and nude looks, with soft colour backgrounds and making a good use of light. This insight was taken by the marketing team to shift the campaign images in this sense and adapt the communication towards light and luminosity, instead of "shine", which in Spanish can have negative connotations in the sense of greasy skin. 
Figure 11: Glow trend analysis across segments

Makeup Style: GLOWY NUDE STYLE

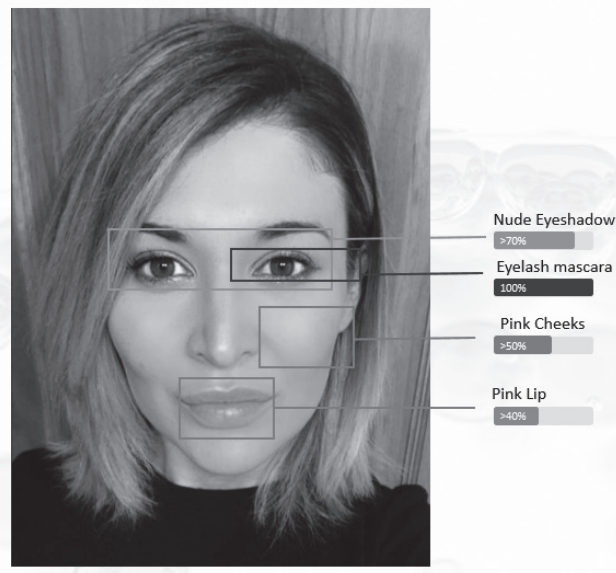

Prevalence among segments:

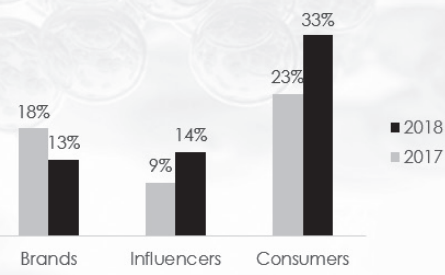

Figure 12: Glow Mon Amour campaign communication center-piece

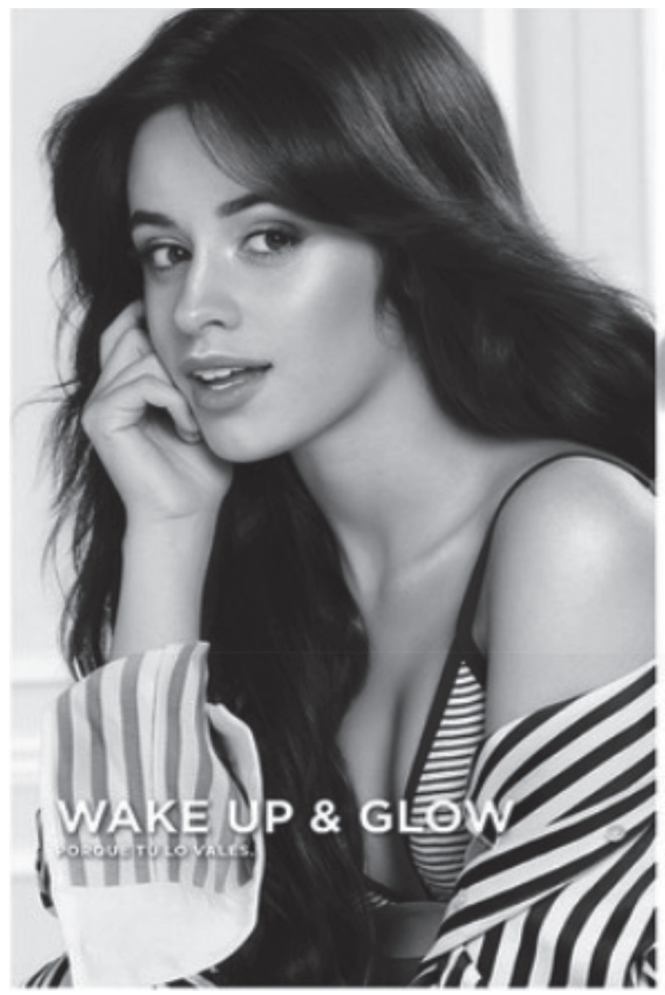

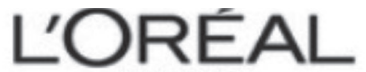

PARIS

\section{NUEVO}

GLOW MON AMOUR

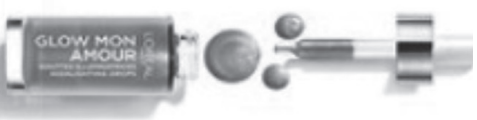

ILUMINADOR EN FORMATO LIOUIDO PARA UN TOQUE DE LUZ NATURAL.

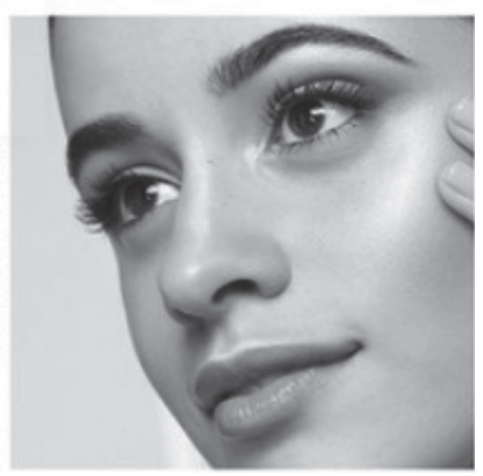


The lookout for the trendiest influencer for the next initiative can be a painful task. Another great output from this study was not only detecting the most representative influencers playing on each segment, but also understanding if they were moving onto a different trend. The following is an example (see Figure 13) of a referent in the pin-up segment that gradually embraced the glow trend, reinforcing the need to play big on this segment:

The configuration of these looks and their evolution over the last two years has enabled LOréal to better understand the makeup consumer's habits and preferences of the Spanish consumer. The two looks that experience growth in usage penetration are also the most sophisticated styles, this sophistication understood as the use of a greater number of makeup categories.

Once these looks and their annual variation were obtained, a verification through Google search (both image and article searches) was performed to validate that there was a growing consumer interest in the Glowy MakeUp makeup style.

\section{2 Research contribution}

From a professional standpoint, the discovery of the abovementioned insights and its application on the company's strategy have been crucial. Besides the specific cases mentioned, the shift on the way L'Oréal now communicates with consumers on social media is sharper, better targeted and lets the brands evolve and adapt to its audience desires and interests.

On a more academic perspective, the process has defined a valid methodology to gather images from visual bases social media networks such as Instagram, in a robust and scalable methodology. Still, it is important to note that this methodology relies on two base assets that are necessary for its success:

\section{Figure 13: Influencer's dashboard and style evolution over time}
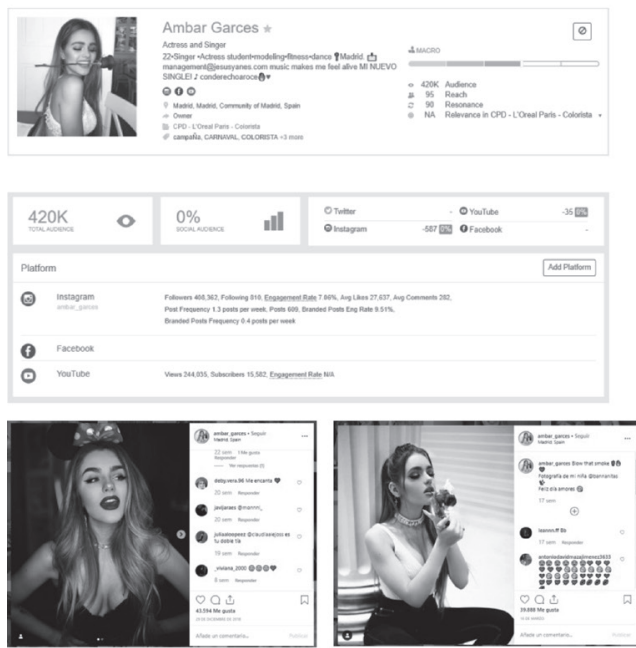
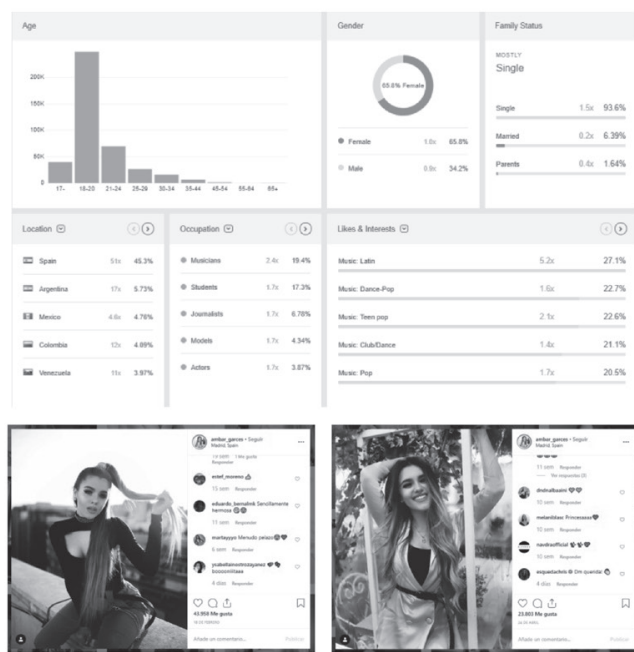
The right knowledge to balance / weight the targets analysed in Instagram (or whatever network) with their real weight in the market, in order to not to overweight / underestimate the relevance of a given segment or trend.

The support to perform a manual coding of the second stage (right after the AI has filtered and pre-analysed and categorized the results).

Hopefully, further development of AI algorithms and tools should enable a less heavy work on the second point abovementioned.

\subsection{Results Summary and Limitations for Future Research}

As above shown, the process yielded the following core results:

- First-hand learnings that could be directly used by marketing teams, and in particular:

- Tribe landscape among make-up consumers in Spain. Looks, products used, and its trend among consumers, influencers and brands, showing the saturated and blank market spaces.

- Interaction with text based learnings to provide a deeper consumer understanding

- Evolution of a given trend over time to adapt and predict future consumer behaviours.

- A deep coded beauty image database that could be used to train AI algorithms in the future for a more powerful, automatized tool. The first milestone of a long process to elevate and automatize the Social Insights function at L'Oréal.

The main limitations faced, as mentioned, are the following:

- The representativeness of Instagram for the Spanish beauty consumer. It was necessary to weight the different segments of the sample to reach the right, balanced conclusions.

- AI algorithms capacity to code and filter images. At a certain stage, it was necessary to introduce human help to validate and perform a deeper coding.

Besides these limitations, we believe there will be difficulties and limitations along this path. Thinking about the future, it cannot be ignored that there is a certain chance that the big players on social networks, led by Facebook, start taking a more proactive attitude towards these practices and set limitations or charges upon its usage. Being conscious of their potential in terms of data richness gives them the absolute power to decide what amount of information is the right one for their interests. As social insights spread and sophisticate, this possibility is growing and in the line of previous API restrictions - such as the one set by Instagram back in 2018- can get tougher in a matter of days and strongly constrain the efforts -and investments- that all of us made in this direction. In this sense, it is key to have an open relationship with the players and develop a social insights function based on common shared knowledge and cooperation.

Besides this uncertainty, the future of Social Insights looks bright despite there is still a long way to go and it cannot be forgotten that the digital environment is so dynamic, it is way too easy to fall behind if you do not adapt quickly. While task of adapting AI to other categories is still there, video is making a very strong irruption and becoming increasingly relevant day-after-day. Therefore, recognition in the videos should be the next frontier in any upcoming social AI project. The platforms that allow sharing this type of content are of great importance 
for the Insights sector, both by audience, as well as by its weight in public investment and influential marketing. Youtube still holds a leading position, although Tik Tok is booming across the world, and Instagram is very proactively shifting its attention to Stories. Current technologies also need to catch up with the stronger re- quirements to image-analyse video, with an enormous amount of single frames to be analysed, plus the added complexity of interpreting voice and context information.

The next company to develop this analytical capacity will have a great advantage over its competition. That is the challenge for social insights!

\section{Bibliography}

Alfonso, A.I., Kurti, L., Pink, S. (2004) Working Images: Visual Research and Representation in Ethnography. London: Routledge.

Azati Software (2019). Image detection, recognition, and classification with machine learning [post online]. Retrieved from https://azati.ai/image-detection-recognition-and-classification-with-machine-learning/

Banks, M. (2018). Using Visual Data in Qualitative Research. Oxford. SAGE.

Chen, C., Dantcheva, A., Ross, A. (2013). Automatic facial makeup detection with application in face recognition. Published in International Conference on Biometrics (ICB) 2013. Retrieved from https://www.semanticscholar.org/paper/Automatic-facial-makeup-detection-with-application-Chen-Dantcheva/fcc6fe6007c322641796cb $8792718641856 a 22 \mathrm{a} 7$ ? citationIntent=background\#citing-papers

Cimpoi, M., Maji, S., Kokkinos, I. (2016). Deep Filter Banks for Texture Recognition, Description, and Segmentation. International Journal of Computer vision. Vol. 118 (1). Retrieved from https://rd.springer.com/article/10.1007\%2F s11263-015-0872-3\#citeas

Del Sole, A. (2018) Introducing Microsoft Cognitive Services. Microsoft Computer Vision Apis Distilled. Apress, Berkely CA.

Hu, Y., Manikonda, L., Kambhampati, S. (2014). What We Instagram: A First Analysis of Instagram Photo Content and User Types https://www.aaai.org/ocs/index.php/ICWSM/ ICWSM14/paper/viewPaper/8118
IAB Spain (2018) Estudio anual de Redes Sociales 2018. Retrieved from https://iabspain.es/wp-content/uploads/estudio-redes-sociales-2018_vreducida.pdf

Kaneshige, T ( 2015). WHY Social Listening Platforms Are Failing . Retrieved from https://www.cio.com/article/287 6295/why-social-listening-platforms-are-failing.html

King, Owen C. (2019). Machine Learning and Irresponsible Inference: Morally Assessing the Training Data for Image Recognition Systems. In: Berkich D., d'Alfonso M. (eds) On the Cognitive, Ethical, and Scientific Dimensions of Artificial Intelligence. Philosophical Studies Series, vol 134. Springer, Cham. Retrieved from https://rd.springer.com/chapter/10.1007/978-3-030-01800-9_14

Malhotra, N.K (1996): Marketing Research. An applied Orientation. $2^{\text {nd }}$ ed. Prentice-Hall International USA

Mane, S. \& Shah, Gauri. (2018). Facial Recognition, Expression Recognition, and Gender Identification. In: Balas V., Sharma N., Chakrabarti A. (eds) Data Management, Analytics and Innovation. Advances in Intelligent Systems and Computing, vol 808. Springer, Singapore. Retrieved from https:// rd.springer.com/chapter/10.1007/978-981-13-1402-5_21

Muhammad, U.R., Svanera, M., Leonardi, R., \& Benini, S. (2018). Hair detection, segmentation, and hairstyle classification in the wild. Image and Vision Computing. Vol.71. Retrieved from https://www.sciencedirect.com/science/article/ pii/S0262885618300143

Mulfari, D., Fazio, M., Celesti, A., Villari, M. (2016). Using Google Cloud Vision in assistive technology scenarios. https:// ieeexplore.ieee.org/abstract/document/7543742 
Delafrooz, N., Rahmati, Y \& Abdi, M. (2019) The influence of electronic word of mouth on Instagram users: An emphasis on consumer socialization framework, Cogent Business E Management, 6(1), 1606973.

Olafenwa, M. (2018). Train Image Recognition AI with 5 lines of code [online article]. Retrieved from https://towardsdatascience.com/train-image-recognition-ai-with5-lines-of-code-8ed0bdd8d9ba

Ramos C.D.L., Lim I.K.Y.U., Inoue Y.C., Santiago J.A., Tan N.M. (2020) An Integration of Image Processing Solutions for Social Media Listening. In: Alfred R., Lim Y., Haviluddin H., On C. (eds) Computational Science and Technology. Lecture Notes in Electrical Engineering, vol 603. Springer, Singapore
Silverman, D. (2016) Qualitative Research. Sage Sage Publications Ltd

Borgatti, Stephen., Everett, M., Johnson, J. (2018) Analyzing Social Networks. Sage Publications Ltd

Sun, C. \& Won-Sook L. (2017). Braid Hairstyle Recognition based on CNNs. Published in IEEE International Conference on Systems, Man, and Cybernetics (SMC). Retrieved from https://pdfs.semanticscholar.org/0aac/036d01c3e 3dd65f7a66a55b46d2bf7324fof.pdf

Seif, G. (2018). Deep Learning for Image Recognition: why it's challenging, where we've been, and what's next [online article]. Retrieved from https://towardsdatascience.com/ deep-learning-for-image-classification-why-its-challenging-where-we-ve-been-and-what-s-next-93b56948fcef 